\title{
Haemolymph Assay and Morphological Changes of Silkworm, Bombyx mori L. (Bombycidae: Lepidoptera) Infected with Bacillus thuringiensis
} var. sotto

\section{Muhammad Zeeshan Nazar*, Ayyan Umer, Zahid Mahmood Sarwar, Faiz Ullah Faiz and Sikandar Hussain}

Department of Entomology, Faculty of Agricultural Sciences and Technology, Bahauddin Zakariya University, Multan, Pakistan.

Abstract | Sericulture is a distinctive field of agriculture in which silkworms, Bombyx mori (Bombycidae: Lepidoptera), are reared on wide range for commercial purpose. Silkworm is susceptible to various pathogenic diseases. Among the all bacterial diseases of $B$. mori, flacherie is injurious disease that is initiated by entomopathogenic bacteria, Bacillus thuringiensis var. sotto (Bts). The impact of this infectious disease is weight loss, reduction in cocoon quality as well as quantity and source of infestation for healthy larva. In current study, the $3^{\text {rd }}$ instar larva of B. mori were fed on the leaves of Morus alba treated with B. thuringiensis until the start of $5^{\text {th }}$ instar and the Total Haemocyte Count (THC) of the Bts infected silkworm's haemolymph were counted. The findings of current research showed that THC was significantly increased at $1^{\text {st }}$ and $2^{\text {nd }}$ day i.e., $5128 / \mathrm{ml}$ and $5704 / \mathrm{ml}$ as compared to control 3047/ml, respectively. Afterwards, THC were rapidly decreased and THC were recorded $1928 / \mathrm{ml}\left(3^{\text {rd }}\right.$ day) and $344 / \mathrm{ml}$ ( $4^{\text {th }}$ day). The results also exhibited the morphological changes of silkworm i.e., infected larva fully filled with $B$. thuringiensis spores with flaccid body and haemolymph liquid impelled leading to mortality. Provide the required temperature and humidity with appropriate hygienic condition to $B$. mori are advised to produce healthy silk.

Received | December 13, 2019; Accepted | March 08, 2020; Published | April 20, 2020

*Correspondence | Muhammad Zeeshan Nazar, Department of Entomology, Faculty of Agricultural Sciences and Technology, Bahauddin Zakariya University, Multan, Pakistan; Email: mzeeshan_93@yahoo.com

Citation | Nazar, M.Z., A. Umer, Z.M. Sarwar, F.U. Faiz and S. Hussain. 2020. Haemolymph Assay and Morphological Changes of Silkworm, Bombyx mori L. (Bombycidae: Lepidoptera) Infected with Bacillus thuringiensis var. sotto. Pakistan Journal of Agricultural Research, 33(2): 212-216. DOI | http://dx.doi.org/10.17582/journal.pjar/2020/33.2.212.216

Keywords | Silkworm, Total haemocyte count, Bacillus thuringiensis, Flacherie and morphology

\section{Introduction}

$\mathrm{M}$ any insects are involved in the production of silk but usually silkworm larva are used at large scale. Approximately, 2500 silkworms are required to produce one pound of raw silk. To meet the need of the massive quantity of silk, these worms are reared worldwide. China followed by India are the leading countries for the silk production and considered the pioneer country to initiated sericulture about 5,000 and 3,000 BC. (Gangopadhyay and Singh, 2008). In Changa Manga, Punjab, Pakistan, sericulture industry is established in 2018 by Chinese private companies
(Published in Dawn, April 15, 2019).

Several diseases are produced in silkworm which results mortality that are mostly occur at $3^{\text {rd }}$ and $4^{\text {th }}$ instar stage of silkworm which may disappoint the Sericulturists. Consequently, by the effects of diseases, both the quality and quantity of cocoon crops are severely septic and losses of revenue (Aruga, 1994).

In the world, no silkworm biotypes are exist that are resistant to diseases or pests. Among all the pathogenic disorders, bacteria play a fatal role to cause diseases and ruin the sericulture industry. The most important June 2020 | Volume 33 | Issue 2 | Page 212 
diseases that infecting the silkworm are, flacherie, grasserie, muscardine and pebrine (Das Gupta, 1950). These diseases cause $70 \%$ loss in silk production. The flacherie is the most vulnerable disease, also known as 'Sotto' which is caused by B. thuringiensis that is a spore forming, soil living and gram-positive bacterium. It is also found naturally on leaf surface, aquatic environment and the midgut of many Lepidopterans caterpillars (Aronson et al., 1986).

Mostly B. thuringiensis are used as biological insecticides to control insect pests by making crystal protein or Cry protein that are attached to epithelial layer of midgut and rupture it (Mullins, 1985). Several physiological and biochemical functions of the insect are accomplished by the extracellular fluid which act as a reservoir and transportation of minerals, moulting, excretion and metamorphosis, furthermore, performed several vital activities including immune system or cellular defence in insect body through phagocytosis and encapsulation (Gad and Alzahofi, 2010).

This detrimental bacteria is considered to the causative agent of 'Flacherie' disease in B. mori that enforce the extreme risk to Sericulture. Due to their distinction in the symptoms, it is often known by many names as shrinking disease, softening disease and faecal disease. Silkworm larvae infected with flacherie stop to feeding by alteration in haemolymph composition along with normal physiological and biochemical transformation in insect tissues also are change (Pawar and Ramakrishnan, 1977; Begum et al., 2004) which lead to convulsions even at very low concentration (0.01\%) and it cause 50\% mortality at the $4^{\text {th }}$ instar stage of lepidopterans larva (Aruga, 1994). Therefore, flacherie is a challenge for silkworm disease management, because it is awkward contest to eliminate pathogens from the silkworm rearing environment (Glaser and Lacaillade, 1924).

The aim of this study to find out the lethal effects of Bacillus thuringiensis var. sotto against silkworm larvae to exhibited the haematological changes in the silkworm and exhibited the morphological changes in the body of infected $B$. mori larva.

\section{Rearing of B. mori} origin) were obtain in packets from Forest, Wildlife

\section{Materials and Methods}

The disease free eggs (roughly 1000) of B. mori (Brazil

and Fisheries Department Multan, Punjab, Pakistan. These eggs were brushed into small petri dishes and reared in the laboratory under $26 \pm 2{ }^{\circ} \mathrm{C}$ with R.H. $72 \pm 5 \%$ and allowed it to hatching. Immediately after hatching, the young ones larva were shifted to trays and fed on chopped $M$. alba leaves until $5^{\text {th }}$ instar larva started as per the recommended rearing practice (Ram, 2000).

\section{Culture division}

At the time of inoculation, ( $3^{\text {rd }}$ instar larva), silkworm larvae were divided into two groups, one group for inoculation and other control group. Each group have five replications and ten larvae in each replication.

\section{Purification of bacteria}

The purification of bacteria includes following steps:

Components of nutrient agar: For isolation and purification of bacterial culture, the following material was taken from the Plant Pathology Lab, Bahauddin Zakariya University (BZU) Multan, Punjab, Pakistan, (i) $0.5 \%$ Peptone; (ii) $0.3 \%$ beef extract/yeast extract; (iii) $1.5 \%$ nutrient agar; (iv) $0.5 \% \mathrm{NaCl}$; (v) $500 \mathrm{ml}$ distilled water.

Preparation of nutrient agar: In $500 \mathrm{ml}$ of distilled water, $14 \mathrm{~g}$ of nutrient agar powder was mixed and allowed it to heating for entirely dissolve all the components at $100{ }^{\circ} \mathrm{C}$ for $5 \mathrm{~min}$. The dissolved mixture are autoclaved at $121^{\circ} \mathrm{C}$ for 15 minutes and allowed it to cool at $4^{\circ} \mathrm{C}$ for 30 minutes. At the end, transferred the nutrient agar into sterile petri dish until the agar has solidified and stored the dish in the refrigerator for processing the study (Daniel and Rusch, 1961).

Bacterial culture: The B. thuringiensis spores were taken from the Plant Pathology Lab, BZU Multan, Punjab, Pakistan. The spores and crystals of $B$. thuringiensis were purified with $1.0 \mathrm{M} \mathrm{NaCl}$ and 0.01 percent Triton X-100 and washed repeatedly with purified water via centrifugation and then shifted to petri dish containing nutrient agar for multiplication.

Inoculation of bacillus thuringienesis: At the time of inoculation, very low concentation of thuringiensis $\left(1 \times 10^{-5} \mathrm{Cell} / \mathrm{ml}\right)$ smeared on fresh mulberry leaves and allowed to fed on second day of $3^{\text {rd }}$ instar larva until the start of $5^{\text {th }}$ instar (Pramanik, 2001).

Preparation of haemolymph sample: After every 24 June 2020 | Volume 33 | Issue 2 | Page 213 
hours post-inoculation, punctured the caudal horn of silkworm larva and collected haemolymph in $1.8 \mathrm{ml}$ PT test vials. The sample were collected from 4 larvae of each replication (2 larvae haemolymph/tube) by insulin syringe $(2 \mathrm{ml})$ (Figure 1b) and preserved the sample in refrigerator at $4^{\circ} \mathrm{C}$ by adding $3.8 \%$ Sodium Citrate as an anti-coagulant to avoid melanisation. A total tube represents one replication collections.

Counting the total haemocyte: Before counting the THC, added $1 \mathrm{ml}$ solution of Phosphate Buffer Saline (anti-coagulant) in it for more clear results and counted the THC of both groups with the help of Neubauer Hemocytometer by taking $10 \mu 1$ sample in micro-pipette. We compared and analysed their differences by counting the cells under Stereo Microscope at 40x magnification.

\section{Statical analysis}

Graph Pad Prism 6 software was used for plotting the graph and Latin Square Design on Statistix 8.1 software was applied on data to find mean value, degree of freedom and standard error.

\section{Results and Discussion}

Fluctuations of total haemocytes count in infected B. mori In B. thuringiensis infected silkworm, the THC decreased significantly i.e. $5128 / \mathrm{ml}$ to $344 / \mathrm{ml}$ from day $1^{\text {st }}$ to day $4^{\text {th }}$ post-treatment respectively, as compared to control group of silkworm (Figure 2). The experiment showed that THC decreased 8.86 times in bacterial infected silkworms as compared to healthy worms. In current experiment, it was also find out that initially THC increased $5158 / \mathrm{ml}$ to $5704 /$ $\mathrm{ml}$ in silkworm (Table 1) due to defensive mechanism and afterwards rapidly decreased (Perveen and Ahmad, 2017).

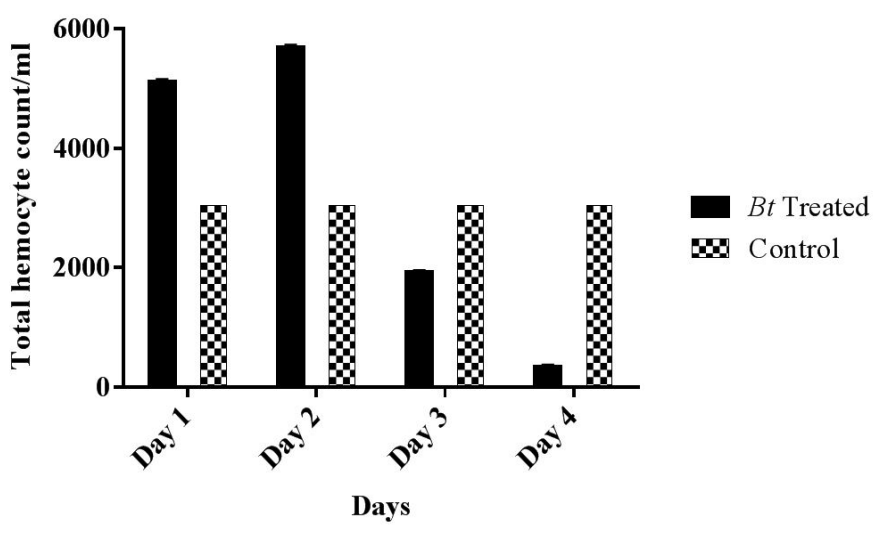

Figure 2: Concentration of total haemocyte count/ml after infection with B. thuringiensis var. sotto.
Table 1: Effect of B. thuringiensis on total haemocyte count and mortality data of B. mori larva.

$\begin{array}{lllllll}\begin{array}{l}\text { Days } \\ \text { Bioassay } \\ \text { groups }\end{array} & \begin{array}{l}\mathbf{T H C} / \mathbf{m l} \pm \\ \mathbf{S . E}\end{array} & \mathbf{d f}^{\mathbf{b}} & \mathbf{N}^{\mathbf{c}} & \mathbf{N}^{\mathbf{d}} & \begin{array}{l}\text { Mortality } \\ \mathbf{( \% )}\end{array} \\ 1^{\text {st }} & B t \text { Treated } & 5128 \pm 8.258 & 4 & 50 & 06 & 12 \\ 2^{\text {nd }} & B t \text { Treated } & 5704 \pm 8.619 & 4 & 50 & 16 & 32 \\ 3^{\text {rd }} & B t \text { Treated } & 1928 \pm 2.408 & 4 & 50 & 37 & 74 \\ 4^{\text {th }} & B t \text { Treated } & 344 \pm 2.607 & 4 & 50 & 48 & 96 \\ & \text { Control group } & 3047 \pm 1.924 & 4 & 50 & 0.00 & 0.00\end{array}$

a'Standard error; 'b degree of freedom; 'Total number of larva exposed

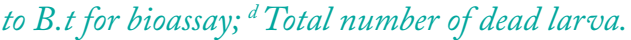

Flacherie is a bacterial disease that infects the silkworm by rupturing the midgut as the spores of B. thuringiensis bind to the epithelial layer of midgut from by producing toxic chemical and proliferate in the haemolymph, disturbing the normal physiological function of the insect. In severe stage, the body is completely filled with spores (Mullins, 1885).

In current examination, it was found that the THC decreased significantly when treated with $B$. thuringiensis that feasts the infection from diseased to healthy silkworm larva and the present results confirm the rapidly propagation of bacteria. Due to defensive mechanism of $B$. mori against $B$. thuringiensis, the Total Haemocytes Count was initially increased in $2^{\text {nd }}$ day after treatment and then sudden decreased of cells on $3^{\text {rd }}$ and $4^{\text {th }}$ days as compared to control group. On $4^{\text {th }}$ day, he $\mathrm{THC}$ reduced in disastrous as a result larva died.

Flacherie infected silkworms are weak and died within $4^{\text {th }}$ to $5^{\text {th }}$ days regarding to the level of infestation. Initially the colour of flacherie diseased larva are light to dark brown (Figure 1c) and lastly turn black (Figure 1d) as compared to control (Figure 1a). Various factors that are involved in flacherie disease like inappropriate condition of environment during incubation of eggs, poor leaves quality, improper handling during rearing of B. mori and lack of food. Due to physiological weakness of silkworm, larva becomes susceptible to various pathogenic diseases due to loss of immunity (Balavenkatasubbaiah and Sivaprasad, 2014). In the current study, it was also examined that due to infection in digestive system and physiological changed in the body of silkworm; the body became fragile, flaccid and shrink. Afterward, yellowish body fluid discharged from the midgut of silkworm by rupturing the integument (Figure 1e). Our results support the findings of 
Ericsson et al. (2009) who studied the response of immune system of the cabbage lopper Trichoplusia $n i$ against $B$. thuringensis. He observed that reduction in Total Haemocytes Count after inoculation of $B$. thuringensis.

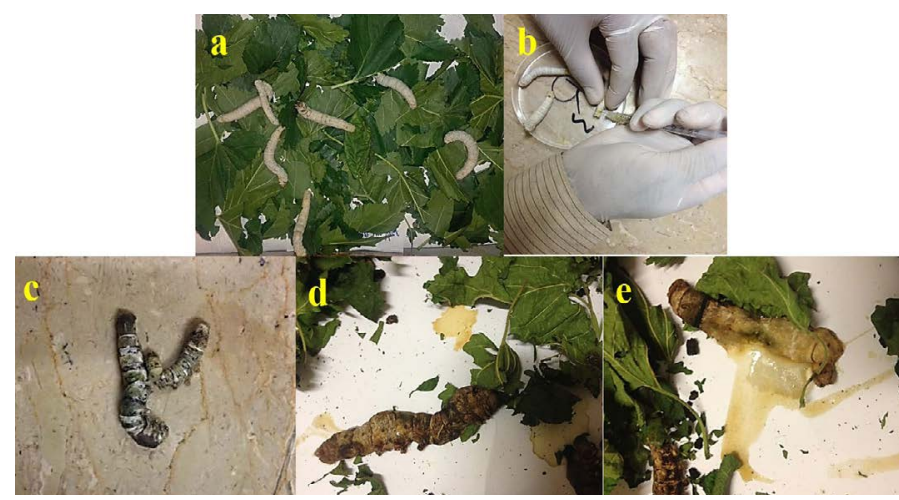

Figure 1: (a) Healthy and uninfected larva of B. mori. (b) Collecting. of Haemolymph from caudal horn of B. mori. (c) Infected larva of $2^{\text {nd }}$ day with light brown colour. (d) Larval color changed to coffee brown on $3^{\text {rd }}$ day. (e) Yellowish body fluid discharged from the midgut of $B$. mori by rupturing the integument after highly infected with $B$. thuringiensis.

As in current study, we examined the morphological changes in infected silkworm that were similar to Poonia (1979) who observed that infected larva with flacherie are entirely lethargic and inactive. The body colour of the larva turned blackish brown, melanisation of the blood and produces bad odour. He also observed that biochemical components are changes in the haemolymph of the silkworm due to flacherie. Lian (1991) also reported that flacherie infected silkworm larva stop to feeding, trembles, paralysis and death. Before death, caterpillar lifts its head. The body colour turned pale and stops the growth and development. At the end, the midgut ruptured and the larval body liquefied. Total haemocytes from $B$. thuringiensis treated larvae of gypsy moth were significantly decreased in number and signs of integument rupture (Broderick et al., 2010).

Anandakumar and Michael (2011) found approximately the same result as described in present study. $\mathrm{He}$ reported that when silkworm larvae were fed orally with Bacillus thuringensis, the total haemocyte count reduced significantly. Flacherie infected silkworm showed $15.3 \%$ decrease in total haemocyte as compared to healthy silkworm larva.

On the basis of above observation, feasibly, the silkworms were not able to feed normally when infected by bacteria and gradually weal down, finally died.

\section{Conclusions and Recommendations}

Present experiment indicates that flacherie disease mostly spread at $3^{\text {rd }}$ and $4^{\text {th }}$ instar stage due to contaminated food and suffocation due to over population. Total haemocyte counts increase at initial stage due to defence mechanism in insect then rapidly reduced. Furthermore, change in morphology and feeding behaviour of flacherie-infected silkworm has also been observed. Initially the colour of flacherie diseased larva is dull white, but it gradually changes to coffee brown or light brown and finally dark brown or almost black. Maintain the required temperature and humidity with proper sanitation are suggested to produce healthy silk.

\section{Author's Contribution}

MZN is the corresponding author. Conceived the idea, performed research, wrote Introduction, methodology, result and discussion and conclusion. AU helped in Haematological assay and rearing of B. mori culture. ZMS wrote Abstract and overall management of the research. FUF helped in statistical analysis and set the References accordingly. SH proof checking of technical Input at every step.

\section{Acknowledgements}

The authors are thankful to ${ }^{1}$ Faculty of Agricultural Sciences and Technology, Department of Entomology, Bahauddin Zakariya University, Multan, Pakistan for providing research facilities. This research did not receive any specific funding.

\section{Conflicts of interest}

The authors declare no conflicts of interest.

\section{References}

Anandakumar, M.D. and A.S. Michael. 2011. Haematology and haemochemistry of silkworm, Bombyx mori L. Infected with Bacillus thuringiensis. Int. J. Environ. 2: 451-457.

Aronson, A.I., W. Beckman and P. Dunn. 1986. Bacillus thuringiensis and related insect pathogens. American Soc. Microbiol. 50: 1-24. https://doi.org/10.1128/MMBR.50.1.124.1986 
Aruga,H., 1994. Principles of sericulture (translated from Japanese). J. Plant Dis. Protect. 3: 3-58.

Balavenkatasubbaiah, M. and V. Sivaprasad. 2014. Flacherie disease and its management in silkworm rearing. central sericultural research and training institute, Mysore.

Begum, H.A., E. Hassan and J. Dingle. 2004. Resistance of Three Different Populations of Mulberry Silkworm (Bombyx mori L.) To Bacillus thuringiensis. J. Plant Dis. Protect. Eugen. Ulmer GmbH Co., Stuttgart 3: 231237.

Broderick, N.A., K.F. Raffa and J. Handelsman. 2010. Chemical Modulators of the Innate Immune Response alter Gypsy Moth Larval Susceptibility to Bacillus thuringiensis. BMC Microbiol. 7: 10: 129. https://doi. org/10.1186/1471-2180-10-129

Daniel, J. and H. Rusch. 1961. The pure culture of Physarum polycephalum on a partially defined soluble medium. Microbiol. 25: 47-59. https:// doi.org/10.1099/00221287-25-1-47

DasGupta, M.R. 1950. Diseases of silkworm monograph on cottage industries. Govt. India. Press, Calcutta 1: 1: 25.

Ericsson, J.D., A.F. Janmaat, C. Lowenberger and J.H. Myers. 2009. Is Decreased Generalized Immunity a Cost of $B t$ Resistance in Cabbage Loopers Trichoplusia ni. J. Invertebr. Pathol. 100: 61-67. https://doi.org/10.1016/j. jip.2008.10.007

Gad,A.A. and N.N.Alzahofi. 2010. Changes in the haemocytes of Bombyx mori larvae (Lepidoptera: Bombycidae) in relation to Escherichia coli and bacillus thuringensis infection. Egypt. Sci. Mag. 6: 15-21.

Gangopadhyay, D. and R. Singh. 2008. A new breeding approach to evolve polyvoltine breed(s) of the silkworm, Bombyx mori L. Using
Parthenogenetic Techniques. Indian J. Sericul. 47: 87-93.

Glaser, R.W. and C.W. Lacaillade. 1924. Rate of horizontal and vertical transmission of Bacillus thuringiensis causing flatcherie disease in the mulberry silkworm Bombyx mori L. J. Econ. Entomol. 17: 486-497.

Lian, L.Y., 1991. Silkworm diseases. Food Agric. Organ. U. N. 4: 28-30.

Mullins, D.E., 1985. Chemistry and physiology of the haemolymph. In Comp. Insect Biochem. Physiol., Perg. Press, N. Y. 3: 355-400. https:// doi.org/10.1016/B978-0-08-030804-3.50015-7

Pawar, V.M. and N. Ramakrishnan. 1977. Biochemical changes in larval haemolymph of Spodoptera litura due to nuclear polyhedrosis virus infection. Indian J. Exp. Biol. 15: 755-758.

Perveen, N. and M. Ahmad. 2017. Toxicity of some insecticides to the haemocytes of giant honeybee, Apis dorsata F. under laboratory conditions. Saudi J. Biol. Sci. 24: 1016-1022. https://doi.org/10.1016/j.sjbs.2016.12.011

Poonia, F.S., 1979. Haemolymph proteins in fifth instar larvae of eri silkworm Philosamia ricini Hutt. after infection with flacherie disease. Indian J. Sericult. 18: 43-47.

Pramanik, A. and A.K. Somchoudhury. 2001. Adverse effect of Bacillus thuringiensis Berliner on silkworm, Bombyx mori L. and other beneficial nontarget organisms. J. Entomol. Res. 25: 53-57.

Raja, R., 2000. Appropriate silkworm rearing technology. Int. J. Environ. Sci. Bishen Singh Mahendra Pal Singh press, Dehradun, India. 1: 289-302.

Ram, R. 2000. Appropriate Silkworm Rearing Technology. Sericulture in India, Bishen Singh Mahendra Pal Singh press, Dehradun, India. 4: 289-302 